\title{
Sciendo
}

Transport and Telecommunication, 2021, volume 22, no. 1, 53-66

Transport and Telecommunication Institute, Lomonosova 1, Riga, LV-1019, Latvia

DOI 10.2478/ttj-2021-0005

\section{SUSTAINABLE MARITIME FLEET MANAGEMENT IN THE CONTEXT OF GLOBAL SULPHUR CAP 2020}

\author{
Sina Atari \\ School of Business and Governance, Tallinn University of Technology, \\ Akadeemia tee 3, 12618 Tallinn, Estonia \\ Sina.Atari@taltech.ee
}

\begin{abstract}
Since the implementation of Emission Control Areas (ECA) in 2015, investment decisions related to abatement technologies represent a crucial task in the maritime industry. Currently, the focus in the maritime sector is on Sulphur reductions due to SECA regulations and the legislative of Global Sulphur Cap that started in 2020. A special challenge appears in maritime fleet management where sets of ships have to be considered, representing portfolios of assets that have to be equipped with a variety of different options of abatement technologies.

Modern portfolio theory has been applied to various economic decisions to achieve an optimal allocation of resources among different investment opportunities. The research investigates and discusses the application of the Markowitz' optimization in the context of SECA regulations for maritime fleets. The optimal investment portfolios are taking into account the three most important compliance options based on the use of low Sulphur fuel, the use of LNG fuel and the use of HFO with a scrubber. The theoretical results are empirically validated by a case of a shipping line operating 10 vessels.
\end{abstract}

Keywords: SECA regulation, Global Sulphur Cap 2020, maritime fleet management, abatement technology, Modern Portfolio Theory

\section{Introduction}

Sustainable or green transportation is generally defined as logistics operations that intensify efforts to limit greenhouse and hazardous gases including Sulphur, carbon dioxide and nitrogen emissions (Hunke \& Prause, 2013). Hence, shipping lines pay increasing attention to the reduction of their carbon footprint and to apply innovative abatement technologies as well as new ship designs. In recent years, the way towards clean and sustainable shipping has been accompanied by several regulations comprising the implementation of Emission Control Areas (ECA) and the Global Cap for Sulphur reductions in ship emissions.

Since 2015, within the ECA zones, the SECA regulations force ship operations to use Sulphur reduced fuel or to install special abatement technologies. These rules have been extended in a slightly softer version to all global ship operations by the Global Cap in 2020. Generally, the new rules make shipping greener, but they also have a huge economic impact on investments, the capital volume and capital risks on the whole shipping industry (Olaniyi \& Prause, 2019). Companies that had the opportunity to operate since 2015 in the SECA zones have gained valuable experience to cope with compliance rules that might simplify the worldwide implementation of the Global Cap rules (Prause \& Olaniyi, 2019). Shipping lines around the world could benefit from the gained knowledge and experiences. However, changes are happening quickly, and it is not just the laws changing the business environment. New and alternative technologies, fuels are all players in the Green shipping evolution. Being part of this change, shipping companies, ports and fuel refineries, production and distribution companies need to make quick major strategic decisions in order to improve compliance vision to the new laws and advance their economic goals.

More than 14,000 ships are participating in the SECA. About 2,200 of them operate $100 \%$ of the time, while more than half of the time 2,700 ships spend sailing in this district (Raza et al, 2019). Nearly all of them have already found a good solution to the new statute. Conventional solutions have been discussed and examined by many scholars. Solutions include Liquefied Natural Gas (LNG), Heavy Fuel Oil (HFO) \& Scrubber, $0.1 \%$ Low sulphur fuel oil (LSFO) and Marine gasoil; LSMGO - Low-sulphur $(<0.1 \%)$ Marine Gas Oil (Olaniyi, 2018). Considering that the Global Sulphur Cap 2020 will affect more than 70,000 ships (Veritas, 2018), this can be both a great opportunity for innovation and growth as well as a major economic threat to companies that have not found the right solution yet. Under the terms of the International Maritime Organization (IMO) maritime pollution (MARPOL) regulation, the 2020 date was subject to a review, to be executed by time in 2018, as to the availability of the required bunker fuel oil for ships. Depending on the outcome of the review, this date could be deferred to January 2025 (Hilmola, 2018). 
However, from an economic point of view, the choice of vessel type and the choice of fuel type for the engine and equipment is still ambiguous and is not a question to be solved easily. Major factors and variables include the best abatement solution for managers and investors to decide on which ship type, model, size, capacity and at what speed considering the direction and sailing area.

Associating the literature part to the research question will lead to the development of a model for the optimal investment solution in green shipping transportation. The model can be generalized to help finding the best solution for next or current investment. This article should be of interest to several stakeholders in the shipping industry, e.g. hedge fund managers, ship-owners and others with a share of real investments. This article proceeds as follows. After reviewing the relevant literature on shipping and financial theory in the section, it shows how investors can recreate Markowitz's presentation of efficient portfolios as the tangencies between LNG ships and Ships running by HFO and scrubber. After the discussion of the data selection and methodology, the capital asset pricing model (CAPM) and portfolio optimization will be used to determine the efficient frontier and the optimized portfolio considering the portfolio weights. Finally, results and recommendations are presented followed by concluding remarks.

\section{Theoretical Background}

The importance of shipping over sea is widely documented, and most commercial goods are still carried out by this form of transport. The United Nations Conference on Trade and Development (UNCTAD) reports that around 80 percent of global trade is transported by sea in terms of volume. In terms of value, this equates to 70 percent. Of that number, 60 percent accounts for marine commerce passes through Asia, with an estimated one-third of global shipping carrying the South China Sea (see, e.g., Team, 2017). The increase in world-wide population and the increased economic activity in recent years have added to the increase in world trade.

With an increasing economic activity comes further economic investments. Investment managers' success depends on how they allocate capital. Creating long-term value and wealth to shareholders is one of the most important objectives of companies (Bezemer et al., 2007). Investment decisions have a significant impact on companies' life cycles. In cases where the decision is important and the number of options is high, it is difficult for investors to make optimal decisions (Cox, 1985). Investors in the capital market face both risk and return factors. Returns are a positive parameter and fluctuations (risk) are a negative parameter in financial investment decision making. Therefore, every investor seeks to invest their capitals in a place where returns are highest and fluctuations (risk) are lowest (Mokhtar et al., 2014).

The main investments in the marine industry are typically divided into two major categories: 1 . Shipping companies and shipping lines, and 2. Ports. Shipping lines, like companies in most industries, have a serious need to invest in expanding market share and customer needs, investing in new technologies to stay ahead of competitors as well to reduce costs and stay competitive. Above all, it is crucial to optimally deal with new laws and adhere to international commitments. This paper links two streams of literature: the seminal theoretical works of Markowitz and the green shipping industry.

\section{Green shipping and abatement technologies}

The policy of launching a green transport system is, in fact, an immediate and obvious solution to reducing pollution from the transportation and shows that any environmentally friendly means of transport does not emit toxic gases or liquid. Launching such a system requires public awareness, public participation, private management as well as innovation and production of ships that use renewable energies such as wind, solar, biofuels and hydroelectricity. These sustainable methods will be a new challenge for the whole industry after SECA regulations (Allwright, 2018). Temporary green shipping will cost a lot and there will be new investments for the respective industries. It also has many benefits, from reducing environmental budgets to improving health, economics and more (Rahm, 2015). In green shipping plans, which aim to reduce environmental pollution, transition to the green transport systems should eliminate Sulphur Oxides emission (SOx) and Nitrogen oxides emission (NOx) as toxic gas. Any action in this regard is a step towards the reduction of Carbon dioxide $(\mathrm{CO} 2)$, which makes up the vast majority of greenhouse gas emissions from the maritime sector.

Green shipping and the whole transport sector in general are main elements in creating a sustainable economy. The production and distribution of green ships will lead to the creation and application of new technologies. This will lead to the creation of more jobs in the maritime transport sector and will contribute to a sustainable economy (Gibbs, 2009). The finance of green projects by introducing new supportive mechanisms has been discussed in the literature. Instruments such as green bonds, green equity and stocks are specifically constructed for this. Sachs et al. (2019) argue that these green finance tools are a promising way to finance or refinance green projects. 
Energy sources such as fossil fuels have devastating effects on health and lead to increased incidences of cancer, cardiovascular diseases and lung diseases. Green shipping will have a great positive impact on health, and it will be beneficial to health and quality of life (Reinhold et al., 2019). This paper reviews two dimensions of green shipping. First everything related to the ships and technologies and second all relevant things related to the green fuels.

Since the 1960s, heavy fuel oil (HFO) has been the main fuel among all marine fuels. While HFO is cheap and available worldwide, it has high viscosity and comes with high degree of pollution (Wang, 2014). Effective in 2015, ships operating within the ECA covering the Economic Exclusive Zone of North America (EEZ), the Baltic Sea Region (BSR), the North Sea, and the English Channel were forced to give up high sulphur fuel. It resulted in the use of Marine Gas Oil (MGO) with allowable sulphur content up to $1,000 \mathrm{ppm}$ (Thomas, 2020). From 2020 onwards, ships sailing beyond ECAs will have to turn to Marine Diesel Oil (MDO) with a sulphur content of up to 5,000 ppm (Mohseni et al., 2019). Enabling the burning of HSFO through the fitment of a scrubber is an attractive and effective alternative.

The uncertainty around fuel prices after the first of January 2020 has been the principal driver of slow decision making by operators. With fuel accounting for up to 40-60\% of a ship's operating costs, choosing the right fuel to run under IMO's new SOx standards will be critical to success next year onwards (Atari \& Prause, 2017). Operators using High Sulphur Fuel Oil (HSFO) have a few options: switch to Low Sulphur Fuel Oil (LSFO) if the engine performance do not drop or invest in upgrading the engine, continue using HSFO with an exhaust scrubber, or convert to alternative fuels such as LNG.

While LNG as fuel is very competitive in term of prices compared to the other available fuels, the use of this kind of fuel is quite limited. The worldwide LNG terminals and distribution stations are not very well established to make it a widely used bunker fuel. This trend is quickly changing however. Its favorable emissions profile makes it an increasingly popular fuel for continental use and, as a result, new reserves of natural gas are being explored aggressively.

LNG's success on affordability was highlighted in new research by Sharples (2019). LNG bunker fuel in Scandinavian markets have historically sold to replace the main competitor (LSFO) at a substantial discount. A shipping classification society expects LNG to take 11 percent of the total bunker fuel market share in 2030 (Shenoi, 2015). The risk for any type of low sulphur fuel remain a higher demand than the supply of it. If the investments in LNG terminals and port tankers do not adjust fast enough it may cause an LNG price explosion (Olaniyi \& Gerlitz, 2019). The export of LNG in 2019 is still not expanded and distributed like the oil market. Qatar and Australia have nearly 45 percent of the world LNG export supply market share (Danilov et al., 2019). Due to the high supply risk, the LNG fuel is not yet reliable as an alternative solution. Albrecht (2015) pointed out that mainly ship owners concern about the supply facility of LNG. The SECA area and far east countries have a superior establishment of LNG facilities and infrastructures; Europe is lagging. Olaniyi et al. (2019) investigated the marine LNG energy market. The developed model promotes a cycle of economically sustainable LNG production and distribution. The study states that to meet the global need for low sulphur fuel for the year 2020 and beyond, low sulphur fuel supply must be increased and expanded. At the present, the world market is divided between different solutions to meet the increasing demand for sulphur-friendly fuels.

On the other hand, as for scrubbers, because they are low-cost to install relative to a whole new propulsion system, the payback comes about three times faster (Olaniyi et al., 2018). Before 2020, the numbers were far less favorable for vessels that spend, say, only half their time in an ECA. The large capital investment required in a retrofit is a major limitation for ship owners. The economic factor changes significantly in favor of new builds rather than retrofits installment (Atari et al., 2019). It seems more economical and more attractive for ship owners to install scrubbers, while LNG propulsion is more feasible on new builds than retrofitting. In several cases it proved to be the case that the payback period is shorter for new LNG equipment. Although LNG still attracts the biggest attention as a Sulphur-free fuel, methanol and biofuels has proven to be a strong alternative and can be a future solution as well (Hansson et al, 2019, Moreira, 2019).

\section{Maritime investment and risks}

Financing and leasing ships have been the center of the attention to ship owners in past decades. Two main decision always have been essential to ship owners: when to buy, and when to sell, similar to capital trade markets (Stopford, 2008). Todd (2019) found that on average, the ship price depends for 30 percent of the total cost on hot rolled steel. Labor force productivity as a crucial factor accounts for 13 percent of total ship value. The trade market for vessels are in many ways similar to freight markets. It can be divided into a primary and secondary market (Wijnolst \& Wergeland, 1996). In fact, the new build ships add to larger capacity to the overall worldwide fleets. On the other hand, the second-hand market offers a transfer of risks. However, the reality is that investing in a new or second-hand ship or any changes to the ship's system 
requires financial capital. Kavussanos \& Marcoulis (2005) concluded that both micro (i.e. company level) and macroeconomic factors contribute to illuminate the shipping capitals return on investment. Kavussanos et al. (2002) studied macroeconomic factors and their models on whole maritime industry. The decision of buying (and investing) new or second-hand vessels is a key investment decision.

Most research on investment topics have been done on capital markets. In fact, few research is focused on maritime economics and investment related issues in maritime industry. Hence, focusing on capital budgeting investment research might solve issues in the maritime industry. Incidentally, the results of valuable research work on classical investment methods in order to criticize the inefficiency have been examined by Bendall \& Stent (2003). Real option and fuzzy methods, replacing the classical net present value (NPV) and internal rate of return (IRR), have recently been applied to model prices in the maritime industry (Atari et al., 2019, Metzger \& Schinas, 2019). Acciaro (2014) has proposed new models by applying the real option investment evaluation theory into smaller ships with different fuel types and propulsions.

Considering the above, where should investors put their allocated capital? Should ship owners invest in a new fleet or simply turn to the shipping capital market investments? Should they invest in shipping industry stocks or raise the necessary capital by active participation in capital market? These questions make the study on shipping stocks more relevant and crucial than before. Concentrating more on the shipping industry investment, Westgaard et al. (2007) specifically studied the commercial ships market and proposed a framework for explaining stock returns based on the capital raising and investment with attention on historical data. Previous studies of risk factors in shipping have concentrated on the returns of shipping stocks. Drobetz et al. (2010) and Grammenos \& Arkoulis (2002) have found betas with lower volatility than the market in the shipping industry in a simple asset pricing model. While the variance of shipping stocks generally is greater than the market, the model shows that stocks typically have betas of less than one.

Apart from investments risks other risks pointing to the financialization of shipping markets with a risk management approach. The risks, which are more related to the transport market, can be defined as the measurable liability for the financial loss arising from unpredicted imbalances between the supply and demand for transport (Karakitsos \& Varnavides, 2014). By including several risk factors, it approximates the real exposure to certain risk. Taking the perspective of a shipping-oriented investor, viewing vessels as financial assets, it is important to mention such a constraint, as shipping is known for its high value assets (large hi-tech vessel will cost more than $€ 200$ million in construction), and its high total-debt-toassets ratio (see Drobetz et al., 2013).

Diversification in investments can help to balance risk. King (1993) implemented new models to account for several common factors on asset pricing and the covariance structure to show how diversification can be used to balance risk. Friend \& Blume (1970) discussed the comprehensive reassessment of the valuation of capital assets under uncertainty. A spinoff of this reconsideration was a theory of equilibrium in the stock market. Blume (1970) proposes two different methods of assessing future performance of stocks or, more technically, of assessing predictive or subjective distributions of future return of investment. Applying a predictive posterior distribution (PPD), it can be shown that the new distributions tend to understate the probability of Extreme Values (EV). This method can be used as a tool for risk management. Especially the models of Nobelists Fama \& French (1993) using three factors portfolios in investment models have received great attention. These models have gained support and have been employed by the financial industry with equity and investment appraisal problems (Leibowitz et al., 1989). The models of Chen et al. (1986) focus on utilizing macroeconomic factors to explain capital market returns. Consequently, they will provide with a starting point for modeling the covariance structure among shipping assets.

\section{Portfolio theory and asset allocation}

The concepts of portfolio optimization and diversification are among the main tools in financial decision making (Rachev et al., 2008). Portfolio optimization problems have been of interest to financial researchers since the early 1952s. Modern Portfolio Theory (MPT) is an investment theory built upon work by Harry Markowitz and was first published in the Journal of Finance in 1952 under the title "Portfolio Selection". MPT has become the main method for financial decision-making and the theory has created an organized paradigm towards forming a portfolio with the highest expected rate of return at a certain level of risk. According to Markowitz' theory, a person can, for a given level of return, minimize portfolio variance by minimizing investment risk, or at a certain level of risk that is tolerable to the investor, one can maximize the expected return, which increases the expected rate of return on the portfolio (Lin et al., 2008). Three quantitative finance pioneers have been awarded the Nobel Prize in 1990 in Economic Science: Merton Miller, William Sharpe and Harry Markowitz for their work on portfolio optimization (Varian, 1993). 
The focus in this article is entirely on the asset itself and excludes specific investment decisions of investors, like, e.g., debt, credit, financing, and leasing. Markowitz' (1952) optimization procedure requires expectations of future returns, variances and covariances. The procedure itself is widely accepted and used by practitioners and academics. Using this approach, investors can expand the basket and add or remove asset from portfolio to gauge if the return per unit of risk can be improved.

The variety of investment methods and the complexity of investment decisions have increased dramatically in recent decades. This widespread growth has created a growing need for inclusive and integrated models. Since Markowitz' ground-breaking work in portfolio investing, an evolutionary process has taken place. The application of mathematical modeling and programming which has introduced extensions of efficient portfolio modelling (Fabozzi et al., 2007). Yu et al. (2012), for example, presented a new model for the problem of multi-period portfolio selection. In this model, the maximum absolute deviation is used to measure risk rather than variance. The risk is controlled in two stages, unlike the traditional method that risk is calculated through variance. First, the risk should be minimized in each period, where the risk is the highest standard deviation of all assets, and in the second, a parameter that represents the highest level of risk over the period is used. The optimal stock portfolio is obtained by solving the above model using dynamic programming.

\section{Methodology}

Although portfolio optimization is widely used, it has not specifically been applied before in the sector of maritime investments. In this article a mixed method of qualitative and quantitative analyses applied to examine the case of portfolio optimization in the shipping industry. It investigates whether a diversified portfolio of ships outperforms in the fleet with minimizing the risk of losses while profiting from diversification opportunities in two major dimensions: fleet mix with more LNG ships or with a higher weight in investments in HFO and scrubber. By default, the total portfolio only consists of LSFO ships in the fleet.

In this article the fuel prices are gathered using Rotterdam port bunker fuel prices (DNV, 2018). LNG prices as a bunker fuel are collected and refined based on the data needed and were calculated based on heating point value considering EU gas price level in Germany (Eurostat, 2019). The collected data was used to determine the annual cost of different fuels used by ships. It means both initial investment and operating costs have been taken into consideration. After introducing fuel data, it evaluate the complete fleet and the combination of ship investment feasibility of the dual fuel propulsion. Using these data, it examine the optimal portfolio with respect to return and risk.

The research is not handling any issue related to operational or major investment decisions. The investment decision, initial investment, macro economical and supply risks are all validated by the empirical data from expert interviews, focus group meetings and case studies. Two different shipping lines with similar ships in their fleets were considered. Most of the ships operate in the SECA. The fleet of both lines is similar in size and numbers. The ships operate between the main ports of Helsinki, Stockholm, Riga and Tallinn and some other ports. The presented case study addresses the current situation of the fuel type and consumption of each ship base on the speed and time of sailing. In the case study, the proposed method as well as optimization of the ten ships for different fleet and modes were implemented. The number of ships with the fuel type was calculated using the modern portfolio theory and the optimal portfolio brought to the light with frontier efficient in the accepted interval. The new fleet mix and combination of different ships in the fleet proposed as a result.

\section{Assumptions}

Investors or shipping lines buying new or second-hand ships were forced to decide before the Global cap 2020 implementation. After the SECA regulation, ship owners needed to decide the strategy toward their fleet management. It means to buy new ships, decide what kind of propulsion, engine and fuels. The company will decide if the ships should use single or dual fuels engine. With a high probability the following three options are among the best solutions for ship owners to choose from: HFO+ scrubber, $\mathrm{LNG}$ or LSFO. On the other hand, to minimize the risk of investment and operation, ship owners will opt for the option of using dual fuel engine. For mixing ships with two different fuels the company has the following possible probabilities in the sample space: (HFO + scrubber) $+\mathrm{LNG}, \mathrm{LNG}+\mathrm{LSFO}$ or $\mathrm{LSFO}+(\mathrm{HFO}+$ scrubber). The company even might choose triple technology engine to have an engine and equipment with the following fuels all together: LNG, LSFO, HFO+ scrubber. The only disadvantage that both dual fuel and triple fuel engine have is a reduced return of capital, because of unused or less used equipment onboard. 


\section{The fleet portfolio}

Portfolio optimization is very sensitive to its inputs. Since it is very difficult to accurately estimate the input parameters correctly, you cannot always rely on the resulting portfolio allocation. Portfolio optimization uses variance minimization. That would not yield the same results due to differing volatility in spot. In the past as the enforcement solution besides of LSFO, ship owners are talking about using scrubber and making an investment in a scrubber with installed capacity necessary. Taking into account the time of operation, the scrubber built and designed based on KW's engine power, after the SECA it is more vital for ships that most of the time sailing in BSR. Currently, to face with Global Cap it will be necessary for all ships using HFO and sailing out of SECA as well. The scrubber will help them to meet the $0.5 \%$ sulphur emission. The study firstly reviews the compliance investment expected return of a scrubber retrofit with a continuance use of HFO with an engine upgrade that involves the boiler, all piping, tankers and auxiliary engines and other necessary equipment. Next, with consideration of different ships which are running by LSMGO or ULSFO ( $0.1 \%$ Sulphur content) or LNG.

The initial investment of the vessel may vary, e.g. initial investments of LNG propulsion for the new ship, tankers and all necessary equipment may be 15 percent costlier than ships with other fuels. This may result in a 5 to 10 percent increase in operating costs. However, when a technology is used more widely by the industry, it might become more cost-effective. Here the focus is primarily on the expected return. Numerous evidence indicates that managers in the industry consider alternate measures such as IRR, payback period, and return duration, along with NPV, real options and many other technics when making capital budgeting decisions. There is also evidence that non-financial criteria can play an important role in the ultimate decision to invest in the maritime industry. Further work can be done to explore scenarios with different objectives, some of which may not be defined in financial terms. Vessel returns will therefore depend on earnings less operating expenses (OPEX) from the saving of expensive fuel to the cheaper alternative bunker fuel. For vessel fleet, the expected return of the fleet return is calculated by the following equation:

$R_{p}=\sum_{i=1}^{n} X_{i} \cdot R_{i}$

where $R_{p}=$ the expected return on the fleet;

$X_{i}=$ the proportion, or weights of total funds invested in $i$;

$R_{i}=$ the expected return for investment $i$.

Equation (1) illustrates the expected return on shipping investments as a function of vessel net earnings and capital appreciation. In order to reflect earnings on the boat, a viable adjustment factor is required. The main assumption is that the ship is running by a single fuel. If it runs by dual fuel, then the composition of portfolio will change. The parameters which are important to get the desired result are:

- Annual fuel consumption

- Annual fuel price average

- Total fuel cost

- Earning from changing the fuel to the cheaper fuel

- Volatility of fuel prices

Since in this article the three compliant fueling options considered for the ship owner consisting of LSFO, HFO plus scrubber (HFO\&S) and LNG we are able to formulate the corresponding formulas for the return and the risk of a certain fleet:

$R_{\text {fleet }}=W_{L S F O} \cdot R_{L S F O}+W_{H F O \& S} \cdot R_{H F O \& S}+W_{L N G} \cdot R_{L N G}$,

where the $\mathrm{W}$ represent the percentage for all kind of ships in the fleet that are propelled with a certain fuel and the $\mathrm{R}$ express the expected rates of return of each type of used fuel. Since the W express only percentages, the overall return of a certain fleet can be gained by multiplying with the number No of ships in the fleet. It has to be kept in mind that a real fleet consists of entire ships, i.e. only those fleets are realistic where the terms W No yield integers. Nevertheless, for calculation reasons the percentage approach is appropriate in order to apply mathematical instruments.

A special reflection is necessary for in the case of LSFO. Since the use of LSFO is considered in the paper as reference point for the use of the other fuels, the return for LSFO is set to the small constant $\varepsilon$ around zero because no additional fuel cost savings can be expected by using the reference fuel, i.e. $R_{L S F O}=\varepsilon$. The same consideration applies for the LSFO when it comes to risk aspects. The standard deviation representing the risk in portfolio theory will be set for the reference point LSFO again to a small constant. In order to avoid calculation problems we can set for the standard deviation the same small constant $\varepsilon$ unequal to zero so that we have $\sigma_{L S F O}=\varepsilon$. Hence, by taking into account these reflections, in the mathematical model we can neglect the return as well as the risk for low-fuel sulfur ships by setting them to a value close but unequal to zero, i.e. in our case to $\varepsilon$. 
With the same percentages for the fleet shares W like in the formula (2) we are able to model the variance of a fleet composition $\sigma 2$ fleet by integrating variance and covariance figure that lead to formula 3 :

$$
\begin{aligned}
& \sigma_{\text {fleet }}^{2}=w_{L S F O}^{2} \cdot \sigma_{L S F O}^{2}+w_{H F O \& S}^{2} \cdot \sigma_{H F O \& S}^{2}+w_{L N G}^{2} \cdot \sigma_{L N G}^{2} \\
& +2 \cdot w_{L S F O} \cdot w_{H F O \& S} \cdot \operatorname{COV}(L S F O, H F O \& S) \\
& +2 \cdot w_{L S F O} \cdot w_{L N G} \cdot \operatorname{COV}(L S F O, L N G) \\
& +2 \cdot w_{H F O \& S} \cdot w_{L N G} \cdot \operatorname{COV}(H F O \& S, L N G) .
\end{aligned}
$$

This formula can be substituted by using the standard deviations of the three fuels together with the correlations of the different fuel types. The resulting formula expresses the fleet variance in form of a quadratic form that stems from a matrix calculation with the correlation matrix of the three fuel in the center $(3 \mathrm{M})$ :

$$
\sigma_{\text {fleet }}^{2}=\left(w_{L S F O} \cdot \sigma_{L S F O}, w_{H F O \& S} \cdot \sigma_{H F O \& S}, w_{L N G} \cdot \sigma_{L N G}\right)\left(\begin{array}{ccc}
1 & r_{12} & r_{13} \\
r_{12} & 1 & r_{23} \\
r_{13} & r_{23} & 1
\end{array}\right)\left(\begin{array}{c}
w_{L S F O} \cdot \sigma_{L S F O} \\
w_{H F O \& S} \cdot \sigma_{H F O \& S} \\
w_{L N G} \cdot \sigma_{L N G}
\end{array}\right) \text {. }
$$

The correlation matrix in the middle of equation $(3 \mathrm{M})$ is symmetric and will be calculated later from historical data about fuel prices. A short matrix calculation reveals that the terms for the fleet variance in formula (3) as well as in formula (3M) yield the same result. Since with these formulas the fleet variance is calculated, we have to take the square root from the fleet variance to achieve the fleet risk, which is expressed in form of the standard deviation.

Coming back to the considerations concerning the return and the risk related to the LSFO by examination of the risk shape - return - curve of the fleet portfolio. One simple sample portfolio fleet composition can consists of $100 \%$ LSFO ships, i.e. a fleet that only consists of LSFO propelled vessels. Such a fleet enjoys the following return and variance values:

$R_{\text {fleet }}=W_{L S F O} \cdot R_{L S F O}=\varepsilon ; \sigma_{\text {fleet }}^{2}=w_{L S F O}^{2} \cdot \sigma_{L S F O}^{2}=\varepsilon^{2}$.

Thus, by letting $\varepsilon \rightarrow 0$ converge to zero it shows that in the return as well as the risk of the portfolio touch the origin, i.e. the point $(0,0)$. Furthermore, knowing that the return and risk functions are continuous, even differentiable, and the return as well as risk increase with growing percentage of HFO plus scrubber and LNG installations thus the efficient portfolio curve of each fleet has the typical logarithmic shape like in figure 1:

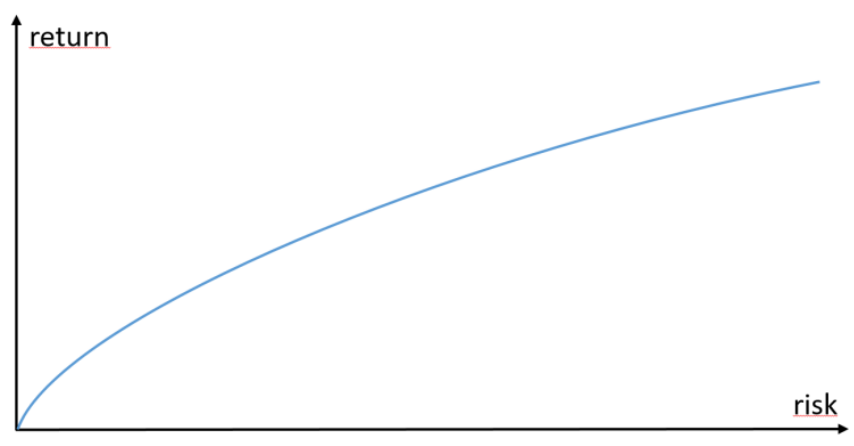

Figure 1. Risk - Return - Portfolio

When we can have portfolios with the same amount of risk in the chart, it can't produce a model that is linear or logarithmic. The chart above highlights that a fleet owner who wants to avoid any risk has to decide for a fleet composition of $100 \%$ LSFO driven vessels and none of HFO plus scrubber nor LNG fueled. Of course, such a fleet composition also is linked to a zero return, i.e., no savings due to smart fuel usage can be expected.

In case of a 50-50 mix of LNG and HFO plus scrubber vessels in the fleet the return expectations are higher, namely the average of the expected savings from LNG and HFO plus scrubber use, which are estimated to be significantly higher than zero. However, this higher return is paid with a higher risk since the standard deviations of LNG and HFO are higher than zero. In this case, until now we have still all three fuel types in our consideration. The value for risk and return of LSFO are nearly zero. We can 
reformulate and facilitate the equations (2) and (3) by focusing only on the two non-LSFO fuels leading to formula (4):

$R_{\text {fleet }}=W_{H F O \& S}^{\prime} \cdot R_{H F O \& S}+W_{L N G}^{\prime} \cdot R_{L N G}$.

$\sigma_{\text {fleet }}^{2}=w_{H F O \& S}^{\prime 2} \cdot \sigma_{H F O \& S}^{2}+w_{L N G}^{2} \cdot \sigma_{L N G}^{2}+2 \cdot w_{H F O \& S} \cdot w_{L N G} \cdot \operatorname{COV}(H F O \& S, L N G)$

With $w^{\prime}{ }_{H F O \& S}+w^{\prime}{ }_{L N G} \leq 1 ; w_{i}^{\prime} \geq 0$ and $w^{\prime}{ }_{L S F O}=1-w^{\prime}{ }_{H F O \& S}-w^{\prime}{ }_{L N G}$.

With this approach the risk level can be lowered by keeping the percentages for LSFO propelled vessels and return of the fleet also decreases due to a certain number of LSFO driven ships that does not generate any savings compared to LSFO use.

The starting point for finding an optimal fleet composition consisting of the three different engine types is the determination of the efficient risk - return portfolios. Therefore, it is necessary to calculate the returns of each propelling type that depend on the underlying spreads between LSFO and the other two fuel types. This leads to the return amounts as well as to the corresponding related risk values for the returns. This indirect approach to calculate the return and risk values for the different engine types based on the underlying spread values is necessary since we do not have market price like in the classical case of the Markowitz portfolio concept (1952).

\section{Findings and discussion}

\subsection{The fleet portfolio}

For a portfolio approach in fleet management it is necessary to agree on a risk measure. Most financial economists use standard deviation (STD) as measure of asset variability (McDonnell, 2008). Hence, by following this traditional way standard deviation is calculated from time series for maritime fuel. The risk for LNG is measured by the annualized volatility of historical EU gas price whereas the risk of HFO is calculated on the base of the volatility of Rotterdam port fuel prices. Since all investigations take place relative to the use of low Sulphur oil the LSFO price plays the role of a reference point, i.e. the volatility of LSFO price in respect to itself delivers a standard deviation of zero as well as an expected return which is also zero. Thus, the calculations deliver the value that are shown in Table 1.

Table 1. Expected return and standard deviation of LNG and HFO-380

\begin{tabular}{|l|l|l|}
\hline Ship type & STD of years return & Average 5 years Return \\
\hline LSFO & 0,00 & 0,00 \\
\hline LNG & 2025400.32 & 8479905.918 \\
\hline HFO-380 & 1004655.911 & 4928894.428 \\
\hline
\end{tabular}

Next important step in constructing a fleet portfolio represents the determination of the spread values of the bunker fuel prices together with their cross correlation to be able to calculate the portfolio risk. This approach is necessary since we do not have market prices for the return values of the three engine types so that the return as well as the risk values have to be calculated based in the different spread prices. After having analyzed the spread values the determination of the corresponding return and risk values is easy to calculate because fuel price fluctuation directly affects the saving cost of operation income. These values are again calculated by executing time series analysis for Rotterdam fuel prices between 2015 and 2020. The table shows a relative high correlation value between the LNG and LSFO spreads whereas the HFO fuel figures are much lower. Table 2 presents the cross correlations.

Table 2. Cross correlation of maritime bunker fuels spread from 2015 to 2020

\begin{tabular}{|l|l|l|l|}
\hline & LSFO & Spread LSFO-HFO & Spread LSFO-LNG \\
\hline LSFO & 1 & & \\
\hline Spread LSFO-HFO & 0.555147458 & 1 & \\
\hline Spread LSFO-LNG & 0.818996114 & 0.315471895 & 1 \\
\hline
\end{tabular}

Now it is possible to draft a chart for a tentative fleet portfolio. The fleet has to be comply this the SECA regulations, i.e. in our case there are the three compliance options consisting of the use of LSFO, HFO plus scrubber as well as LNG. Since a considered fleet consists of ships with three different 
compliance options, each possible fleet composition can be represented by a 3-dimensional vector $(\mathrm{x}, \mathrm{y}, \mathrm{z})$ with non-negative percentage figures that sum up to $100 \%$. In a concrete case of $\mathrm{n}$ ships a multiplication of the three components of the vector yields an approximate composition of the fleet. Hence, a draft for the shape of the portfolio based on the calculated returns, standard deviations and cross correlations can be drafted by considering the subset of 3-dimensional vectors that consists of percentages that are multiples of $10 \%$. This set of vectors includes the vectors LSFO $(100 \%)$, HFO $(0 \%)$, LNG $(0 \%)$ which is located at points 0.0 and in front in contrast to the lowest portfolio at the highest level of the chart representing the most risky portfolio with highest amount of return it includes this combination and the weight of the assets are LNG (100\%), HFO (0\%), LSFO $(0 \%)$. This set of vectors consists of 68 elements and drafts the fleet portfolio. The graph of this enumeration is presented in figure 2 with the standard deviation on the $\mathrm{x}$-axis and the return on the $\mathrm{y}$-axis.

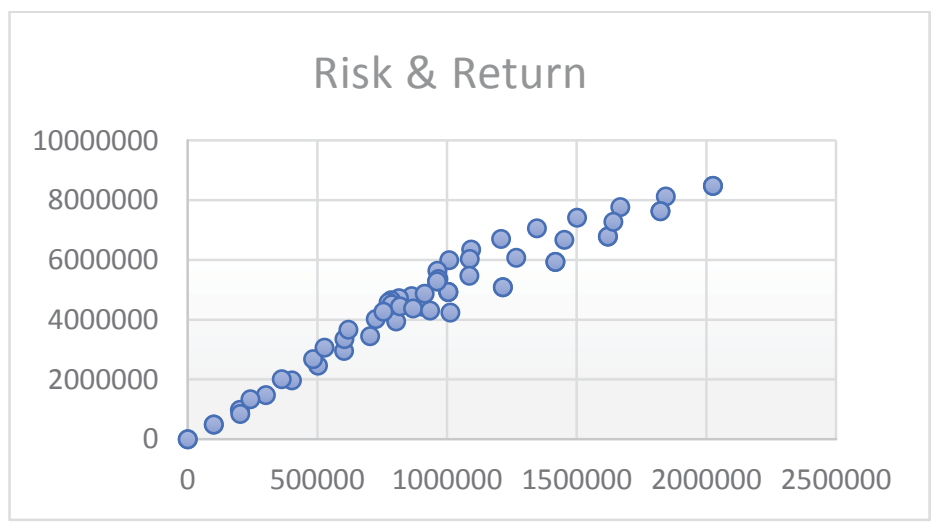

Figure 2. Result for three type of ships as an asset - Risk and Return

The result turn out there is positive relationship in terms of risk and returns. The higher return the amount of risks increases with the same return. The relationship between portfolios are positive, strong and linear. In this case it can interpret, the higher the percentage of LSFO vessels in the fleet portfolio, the lower the rate of return but also lower the risk level. In case of the description of a real fleet there are two issues need to be discussed. First, the number of fleet compositions might be higher and second, not all vectors that are composed of percentages might lead to a real fleet composition, because ships can be only represented by integers. Nevertheless, the shape of a real portfolio will be always close to the situation depicted in figure 2 since the underlying parameters of the shape are the return, the standard deviations and the cross correlations and these parameters not depend on the number of ships in fleet.

The efficient portfolio can be constructed from the results of figure 2 by connecting the upper portfolio point for each risk value. From the graph of figure 2 it is furthermore visible that the efficient portfolio is the superposition of three different curve, namely a linear part between the risk values zero to ca. $750 \mathrm{t} €$, then the upper part of a first parable between ca. $750 \mathrm{t} €$ and $960 \mathrm{t} €$ and finally a second parable starting from ca. $960 \mathrm{t} €$. The first part of the efficient portfolio is characterized by low risk starting from zero up to a risk level of about $750 \mathrm{t} €$. In this section the usage of LSFO dominated the fleet composition yielding low investment risks together with low fuel cost savings, i.e. low return rates. The two upper risk parts are dominated by fleet compositions with high shares of HFO plus scrubber and LNG engines in the fleet. The determination of optimal fleet portfolios require the formulation of a decision approach. The theory offers different decision rules starting with the analysis of a linear risk prime as well as the evaluation of the return on investment approach. The classical methodology of the consideration of a Capital Market Line (CML) like proposed in portfolio theory is not fully transferable to the situation of fleet management.

\subsection{Determination of an optimal fleet portfolio}

There exists no unique approach to determine an optimal fleet portfolio. Like already mentioned, the CML concept from classical portfolio theory is not directly applicable since the concept of real riskfree capital such as free liquid cash or bond, which delivers a unique touching point with the efficient portfolios. Consequently, there does not exist the Sharpe ratio and the corresponding tangency portfolio. However, two other classical approaches in risk theory are able to deliver optimal portfolios, i.e. the 
concept of the maximal risk prime with certain risk slope and the consideration of a modified return on investment (ROI) (Kendall \& Rollins, 2003).

Concerning the maximal risk prime leads to the analysis of the touching point between the efficient portfolio and the line including the point $(0,0)$. Such a line with the highest slope touching the efficient portfolio represents the fleet composition generating the highest risk prime since this touching point represents the composition with the highest ratio return per risk units. Undoubtedly, the origin $(0,0)$ has to be excluded from the consideration. A detailed calculation delivers as such optimal fleet composition with highest linear risk prime. The point $(2,025,400.32,8,479,905.92)$ representing a fleet composition of $(0 \% \mathrm{LSFO}, 0 \% \mathrm{HFO}, 100 \% \mathrm{LNG})$. By following the maximal risk prime approach it has to be kept in mind that in this case only considered discrete portfolios since a fleet composition can barely consist of integer numbers of ships. Furthermore, literature discusses beyond linear risk prims also other type of decision functions (Goerlandt \& Montewka, 2015).

The ROI approach considers for each fleet composition the total investment amount of the fleet abatement equipment and related this amount in form of a ROI to the expected returns, i.e. one considers the ratio of the total return to the total investment sum. The optimal fleet composition is represented by those point with the highest ROI ratio. In case of several points on the efficient portfolio curve with the same ROI as optimal fleet composition that point with the lowest risk value is chosen. The result with consideration of four million Euro free cash (the amount which not invested) on scrubber equipment, and 8 million Euro the amount which not invested on LNG equipment's and divert them to the portfolios and the point of touching can be our market portfolio with highest Sharpe ratio, which has the average return and average STD.

The purpose of this solution could be measure reward to risk of expected return, which was measured by the slope of the lending and borrowing amount on CML and then pointing on the expected return. But in the end the solution is to get the minimum variance portfolio from the efficient portfolios on the curve. As a result, portfolios that are both high-risk and low-income due to low sulfur fuel are scattered at the bottom of the chart. As always, the Minimum Variance portfolio is at the left-most tip of the efficient frontier curve in the top rated return portfolios. However, this is not enough to solve this problem, and we also need to choose the optimal portfolio from them after building the built-in portfolios. To solve this problem, the following mathematical solution can be found to find the optimal portfolio with an unlimited number of assets, which is based on the Lagrange multiplier.

Where the $\lambda$ is a constant value. By analysing the possible fleet portfolios some special observations can be made. First, the risk averse portfolio has a highest expected return and risk that is between the other 3 asset portfolios, and notably does lie on the efficient frontier. The results can be used to make a performance appraisal of the portfolio manager. A portfolio's expected return is equivalent to the portfolio's weighted average return on individual assets. Markowitz also presented the importance of the correlation between two assets. In general, as a primary decision, a rational investor should seek to minimize portfolio risk and maximize return by combining less than perfectly correlated assets. Applying this theory to a maritime industry and risky assets, one can derive an efficient frontier of dominant portfolios in a mean-variance plot. The model's goal is to determine the leverage of each single asset with an offsetting gain or loss within the group of assets, thereby hedging the total portfolio exposure for the agreed level of risk compared to the estimated portfolio return rate. Simply replacing the ship investment in a minimum variance portfolio as a risky asset, the portfolio the same as stock market when traded in the portfolio the risk can be hedged. Since most of the high return high risk portfolios consist of two assets, therefore to find the exact minimum variance portfolio allowance for two assets, employed the following equation of minimum variance of optimal portfolio:

$$
W=\frac{\left(\sigma_{L N G}^{2}-\sigma_{L N G} \sigma_{S C R} \rho_{L N G, S C R}\right)}{\left(\sigma_{L N G}^{2}+\sigma_{S C R}^{2}-2 \sigma_{L N G} \sigma_{S C R} \rho_{L N G, S C R}\right)} .
$$

The optimal portfolio variance with weights and standard deviations:

$$
\sigma_{P}^{2}=w_{L N G}^{2} \sigma_{L N G}^{2}+w_{S C R}^{2} \sigma_{S C R}^{2}+2 w_{L N G} w_{S C R} \sigma_{L N G} \sigma_{S C R} \rho_{L N G, S C R}
$$

The optimal portfolio based on the efficient market hypothesis:

$$
\begin{aligned}
\frac{\mathrm{d} \sigma}{\mathrm{d} x} & =\frac{\left(\mathrm{E}\left(\mathrm{r}_{\mathrm{SCR}}\right)-r_{f}\right) \times \sigma_{\mathrm{LNG}}^{2}-\left(\mathrm{E}\left(\mathrm{r}_{\mathrm{LNG}}\right)-r_{f}\right) \times \sigma_{\mathrm{LNG}} \sigma_{\mathrm{SCR}} \rho_{\mathrm{LNG}, \mathrm{SCR}}}{\left(\mathrm{E}\left(\mathrm{r}_{\mathrm{SCR}}\right)-r_{f}\right) \times \sigma_{\mathrm{LNG}}^{2}+\left(\mathrm{E}\left(\mathrm{r}_{\mathrm{LNG}}\right)-r_{f}\right) \times \sigma_{\mathrm{SCR}}^{2}-\left(\mathrm{E}\left(\mathrm{r}_{\mathrm{SCR}}\right)-r_{f}+\mathrm{E}\left(\mathrm{r}_{\mathrm{LNG}}\right)-r_{f}\right) \times \sigma_{\mathrm{LNG}} \sigma_{\mathrm{SCR}} \rho_{\mathrm{LNG}, \mathrm{SCR}}} . \\
\mathrm{W}_{2} & =1-\mathrm{W}_{1} .
\end{aligned}
$$


Based on this, portfolios with two assets were created and low correlation portfolios are shown in the chart below. This is indicated by the main point of mean-variance and the color of the line in Efficient Frontier changes accordingly. In Figure 3, the portfolios in blue represent portfolios with high risks and low return, while the red colour line of efficient frontier represents portfolios with high return and high risk, indeed this is based on the analysis of selected portfolios of the total portfolios. The point where the blue and red lines touch on the efficient frontier will be our optimal portfolio, the so-called minimum variance portfolio. To control entirely risks together, the portfolio managers can add to the portfolios of ships by LSFO and replace other ships with LSFO ships. Those ships will not add to the savings and generate extra income for the fleet, they can help shipping line to cope with other probable risks.

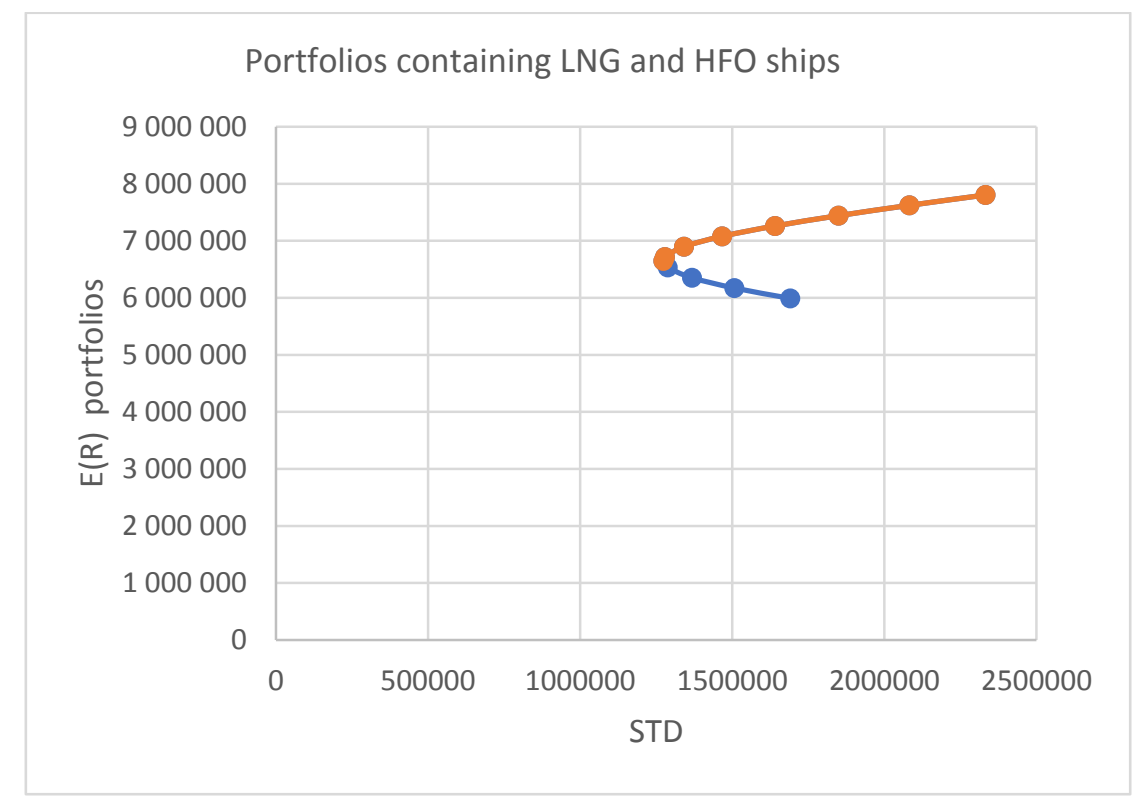

Figure 3. Efficient market portfolio, separated risky portfolio from low risk

The result, as illustrated in Table 3, shows the necessary investments with actual fuel prices in the current market and the forecast for next five years. The optimal solution for this case study with fleet of ten ships is the so-called market efficiency portfolio. According to Markowitz' optimization the optimal portfolio of our case study consists of four ships with LNG and six ships with high sulphur using the scrubber on board.

Table 3. Final result for the optimal portfolio consisting of ten ships

\begin{tabular}{|l|l|l|c|}
\hline No & Fuel type & Portfolio weight & Number of ships in the portfolio \\
\hline $\mathbf{1}$ & LNG & $3.664 \approx 4$ & 4 \\
\hline $\mathbf{2}$ & High Sulphur & $6.333 \approx 6$ & 6 \\
\hline & & Total & 10 \\
\hline
\end{tabular}

Shipping lines aim to have an optimum fleet/portfolio for better utilization and higher operation efficiency. The ship owners should be able to keep the fleet as a minimum to cover fixed expenses. A popular way of making such a fleet with different ship mixes can be seen in the different fleets holding the different assets. Among them RORO, ROPAX beside of tanker, dry bulk and containerships are the most prevalent. The aim of making such a wide range of fleets was previously to cover sailing times and routes. However, risk facing and risk management also has been added to the options of making a wider range of fleet. Markowitz' modern portfolio theory can provide a good solution to optimize current fleet of shipping lines. It can consider the volatility of fuel price, steel price, labour force availability and salaries and other raw materials and additional costs that can affect the operating cost and initial investment.

The fundamental goal of modern portfolio theory is to optimally allocate investment capital among different assets. The modern portfolio theory can be a suitable approach for investors currently coping with the new regulations. In future research this optimization model can be tested on different shipping 
lines with different fleet sizes, ship dimensions and volumes. Employing Markowitz' theory can shift the focus of investors from traditional models to new models based on modern portfolio theory. In this study, the focus was on smaller shipping lines with most of the cruise and ferry ships with roughly the same size and similar vessels in their fleet. New types of fleet portfolio construction can be tested to add more green and suitable vessels which are run by so-called wind vessels, either with ethanol, methanol, biodiesels fuels, or other green or low sulphur fuels. It should take into consideration that such a green fuel, like LNG, have no problems with supply, distribution, storage and ports infrastructure, and have a broad utilization plan, which requires a serious attention of the companies, communities and professionals active in the field.

Wang and Notteboom (2014) reviewed more than 33 studies in the field of LNG as the main fuel of the ship, concerning its advantages and disadvantages have been well addressed. The results of their literature review showed that over the last five years LNG was favourable and suggest that it could make investors focus more on this fuel in the shipping industry, i.e. the LNG solution seems to be promising. However, according to the result of this paper in the case study, the weight for HFO use together with a scrubber is still higher than LNG for the optimal fleet portfolio. Assuming similar price spread changes between LNG and other IMO-compliant marine fuels, new built LNG-driven ships seems to be under current conditions the most favourable choice for ship owners. The results this research revealed as well that the major obstacle for quicker grow of LNG-driven vessels is related to the lack of investments in infrastructure and LNG distribution, i.e. the general availability of the fuel.

The research also complements the investigations of Kavussanos and Visvik (2016) who developed new models of financial management in maritime industry by neglecting risk aspects. The results of the portfolio approach in sustainable fleet management provides a new model for risk management model in the sustainable shipping industry that fills this gap in risk management. Finally, the optimal solution of the fleet portfolio is gained by approximation of integer solutions; here further research from the area of discrete mathematics is necessary to offer an algorithm to solve to portfolio problem with an optimal point having integer coordinates.

\section{Conclusion}

The research provides a new model for investment and risk assessment for fleet management in maritime industry. Until now, after the implementation of SECA regulations and the 2020 Global CAP, most of the vessels turned from low-cost high Sulphur fuel to expensive compliant marine fuel like MDO or LSFO, others retrofitted their vessels for the use of LNG or scrubbers. Since the prices of all compliant fuels are subject to high volatility as well as the correlations between them, ship owners face complex investment decisions for compliance. The paper analyse and discusses sustainable investment decisions for maritime fleets by following a portfolio approach in order to provide a model together with an optimal solution and an risk assessment for an investment decision in shipping industry.

The findings are based on Markowitz' approach of modern portfolio theory and the results show that the elaborated model has the ability to optimally allocate and distribute sustainable investment capital for fleets of shipping companies. The considered fleets consist of vessels using different types of fuels and engines together with potential abatement technologies. The different compliance options of the fleet and their interconnection are evaluated by spreads of fuel prices together with their correlations. The deducted portfolio model facilitates investment decisions for fleet owners and leads to optimal solutions by assessing return and risk aspects. The fleet portfolio model is easily transferable to different frame conditions and supports maritime fleet managers and ship owners to optimise their sustainable investment decisions in the context of green shipping.

\section{References}

1. Acciaro, M. (2014) Real option analysis for environmental compliance: LNG and emission control areas. Transportation Research Part D: Transport and Environment, 28, 41-50.

2. Albrecht, J. (2015) Stakeholder involvement in developing LNG as a ship fuel in the Baltic Sea region.

3. Allwright, G. (2018) Commercial Wind Propulsion Solutions: Putting the 'Sail' Back into Sailing. In Trends and Challenges in Maritime Energy Management, pp. 433-443. Springer, Cham.

4. Atari, S., Bakkar, Y., Olaniyi, E. O., \& Prause, G. (2019) Real options analysis of abatement investments for sulphur emission control compliance. Entrepreneurship and Sustainability Issues, 6(3), 1062-1087. 
5. Atari, S., \& Prause, G. (2017) Risk assessment of emission abatement technologies for clean shipping. In: International Conference on Reliability and Statistics in Transportation and Communication, pp. 93-101. Springer, Cham.

6. Bendall, H., \& Stent, A. F. (2003) Investment strategies in market uncertainty. Maritime Policy \& Management, 30(4), 293-303.

7. Bezemer, P. J., Maassen, G. F., Van den Bosch, F. A., \& Volberda, H. W. (2007) Investigating the Development of the Internal and External Service Tasks of Non-executive Directors: the case of the Netherlands (1997-2005). Corporate Governance: An International Review, 15(6), 1119-1129.

8. Blume, M. E. (1970) Portfolio theory: a step toward its practical application. The Journal of Business, 43(2), 152-173.

9. Carter, D. A., Dare, W.H. \& Elliott, W.B. (2002) Determination of Mean-Variance Efficient Portfolios Using an Electronic Spreadsheet, Journal of Financial Education, 28(3), 63-78.

10. Chen, N. F., Roll, R., \& Ross, S. A. (1986). Economic forces and the stock market. Journal of Business, 383-403.

11. Cox, J. C., \& Rubinstein, M. (1985) Options markets. Prentice Hall.

12. Danilov, R., Arabyan, M., \& Usov, D. (2019) Influence of technologies on LNG market development. In IOP Conference Series: Materials Science and Engineering, 537(4), p. 042030. IOP Publishing.

13. DNV, G. (2018) Current price development oil and gas.

14. Drobetz, W., Schilling, D., \& Tegtmeier, L. (2010) Common risk factors in the returns of shipping stocks. Maritime Policy \& Management, 37(2), 93-120.

15. Drobetz, W., Gounopoulos, D., Merikas, A., \& Schröder, H. (2013) Capital structure decisions of globally-listed shipping companies. Transportation Research Part E: Logistics and Transportation Review, 52, 49-76.

16. Eurostat (2019) Natural gas price statistics. Retrieved from: https://ec.europa.eu/eurostat/statisticsexplained/index.php/Natural_gas_price_statistics\#Natural_gas_prices_for_nonhousehold consumers.

17. Fama, E. F., \& French, K. R. (1993) Common risk factors in the returns on stocks and bonds. Journal of financial economics, 33(1), 3-56.

18. Friend, I., \& Blume, M. (1970) Measurement of portfolio performance under uncertainty. The American Economic Review, 60(4), 561-575.

19. Gibbs, D. (2009) Sustainability entrepreneurs, ecopreneurs and the development of a sustainable economy. Greener Management International, 55.

20. Grammenos, C. T., \& Arkoulis, A. G. (2002) Macroeconomic factors and international shipping stock returns. International Journal of Maritime Economics, 4(1), 81-99.

21. Hansson, J., Månsson, S., Brynolf, S., \& Grahn, M. (2019) Alternative marine fuels: Prospects based on multi-criteria decision analysis involving Swedish stakeholders. Biomass and Bioenergy, 126, 159-173.

22. Hilmola, O. P. (2018) The Sulphur Cap in Maritime Supply Chains: Environmental Regulations in European Logistics. Springer.

23. Hunke, K.; Prause, G. (2013) Management of Green Corridor Performance. Transport and Telecommunication, 14 (4), 292-299. DOI 10.2478/ttj-2013-0025.

24. Karakitsos, E., \& Varnavides, L. (2014) Maritime economics: A macroeconomic approach. Springer.

25. Kavussanos, M. G., \& Marcoulis, S. N. (2005) Cross industry comparisons of the behaviour of stock returns in shipping, transportation and other industries. Research in Transportation Economics, 12(4), 107-142.

26. Kavussanos, M. G., Marcoulis, S. N., \& Arkoulis, A. G. (2002) Macroeconomic factors and international industry returns. Applied Financial Economics, 12(12), 923-931.

27. Kavussanos, M. G., \& Visvikis, I. D. (Eds.). (2016) the international handbook of shipping finance: theory and practice. Springer.

28. King, A. J. (1993) Asymmetric risk measures and tracking models for portfolio optimization under uncertainty. Annals of Operations Research, 45(1), 165-177.

29. Leibowitz, M. L., Sorensen, E. H., Arnott, R. D., \& Hanson, H. N. (1989) A total differential approach to equity duration. Financial Analysts Journal, 45(5), 30-37.

30. Lin, C. M., Phillips, R. D., \& Smith, S. D. (2008) Hedging, financing, and investment decisions: Theory and empirical tests. Journal of Banking \& Finance, 32(8), 1566-1582.

31. Markowitz, H. (1952) Portfolio Selection, The Journal of Finance, 7(1), p. 77-91.

32. Markowitz, H. (1959) Portfolio selection: Efficient diversification of investments, 16. New York: John Wiley. 
33. McDonnell, P. (2008) Optimal Portfolio Modeling: Models to Maximize Returns and Control Risk in Excel and $R, 306$. John Wiley \& Sons.

34. Mohseni, S. A., van Hassel, E., Sys, C., \& Vanelslander, T. (2019) Economic evaluation of alternative technologies to mitigate Sulphur emissions in maritime container transport from both the vessel owner and shipper perspective. Journal of Shipping and Trade, 4(1), 15.

35. Mokhtar, M., Shuib, A., \& Mohamad, D. (2014) Mathematical programming models for portfolio optimization problem: A review. International Journal of Social, Management, Economics and Business Engineering, 8(2), 443-450.

36. Moreira, P. J. P. (2019) Shipping and sustainability liquefied natural gas as an alternative fuel: evidence from Portugal.

37. Olaniyi, E. O., \& Gerlitz, L. (2019) LNG maritime energy contracting model. Entrepreneurship and Sustainability Issues, 7(1), 574-594.

38. Olaniyi, E. O.; Prause, G. (2019) SECA regulatory impact assessment: Administrative burden costs in the Baltic Sea Region. Transport and Telecommunication, 20 (1), 62-73. DOI 10.2478/ttj-2019-0006.

39. Olaniyi, E. O., Prause, G., \& Boyesen, J. (2018) The Impact of SECA Regulations on Clean Shipping in the Baltic Sea Region. In: Trends and challenges in maritime energy management, pp. 309-323. Springer, Cham.

40. Olaniyi, E. O., Atari, S., \& Prause, G. (2018) Maritime energy contracting for clean shipping. Transport and Telecommunication Journal, 19(1), 31-44.

41. Prause, G.; Olaniyi, E. O. (2019) A compliance cost analysis of the seca regulation in the Baltic Sea. Entrepreneurship and Sustainability Issues, 6(4), 1907-1921. DOI 10.9770/jesi.2019.6.4(26).

42. Rachev, S., Ortobelli, S., Stoyanov, S., Fabozzi, F. J., \& Biglova, A. (2008) Desirable properties of an ideal risk measure in portfolio theory. International Journal of Theoretical and Applied Finance, 11(1), 19-54.

43. Rahm, S. (2015) The costly future of green shipping. London: Schroders.

44. Raza, Z., Woxenius, J., \& Finnsgård, C. (2019) Slow Steaming as Part of SECA Compliance Strategies among RoRo and RoPax Shipping Companies. Sustainability, 11(5), 1435.

45. Reinhold, K., Järvis, M., \& Prause, G. (2019) Occupational health and safety aspects of green shipping in the Baltic Sea. Entrepreneurship and Sustainability Issues, 7(1), 10-24.

46. Sachs, J. D., Woo, W. T., Yoshino, N., \& Taghizadeh-Hesary, F. (2019) Handbook of Green Finance: Energy Security and Sustainable Development.

47. Schinas, O., \& Metzger, D. (2019) A pay-as-you-save model for the promotion of greening technologies in shipping. Transportation Research Part D: Transport and Environment, 69, 184-195.

48. Sharples, J. (2019) LNG supply chains and the development of LNG as a shipping fuel in Northern Europe.

49. Shenoi, R.A., Bowker, J.A., Dzielendziak, A.S., Lidtke, A.K., Zhu, G., Cheng, F., Argyos, D., Fang, I., Gonzalez, J., Johnson, S. and Ross, K., (2015) Global Marine Technology Trends 2030.

50. Stopford, M. (2008) Maritime Economics/M. Stopford.

51. Team, C. P. (2017) How much trade transits the South China Sea? China Power.

52. Thomas, J. F., Sluder, C. S., Kass, M. D., \& Theiss, T. (2019) A Guide to Fuel, Lubricant, and Engine Concerns Relative to the IMO 2020 Fuel Oil Sulfur Reduction Mandate. ORNL, 1406.

53. Todd, D. (2019) The world shipbuilding industry. Routledge.

54. Varian, H. (1993) A portfolio of Nobel laureates: Markowitz, Miller and Sharpe. Journal of Economic Perspectives, 7(1), 159-169.

55. Veritas, D. N. (2018) Global Sulphur Cap 2020-extended and updated.

56. Wang, H. (2014) The end of the era of heavy fuel oil in maritime shipping. The International Council on Clean Transportation (ICCT). Retrieved from: http://www.theicct.org/blogs/staff/endera-heavy-fuel-oil-maritime-shipping (accessed: 17.08.15).

57. Wang, S., \& Notteboom, T. (2014) The adoption of liquefied natural gas as a ship fuel: A systematic review of perspectives and challenges. Transport Reviews, 34(6), 749-774.

58. Westgaard, S., Frydenberg, S., Mitter, K. W., \& Jensen, E. F. (2007) Economic and Financial Risk Factors and Tanker Shipping Stock Returns. Available at SSRN 969910.

59. Wijnolst, N., \& Wergeland, T. (1996) Shipping. Delft University Press.

60. Yu, C. K., Yip, T. L., \& Choy, S. K. (2019) Optimal portfolio choice for ship leasing investments. Maritime Policy \& Management, 46(7), 884-900. 